\title{
The Effect Of Controlling Hyperglycemia On The Morbidity And Mortality Of Intensive Care Unit (ICU) Patients
}

\author{
Hiyam Al-Haqeesh \\ Royal Medical Services, Jordan \\ Abla Al-Bsoul \\ The University of Jordan, Jordan \\ Hussein Shalan \\ Aysha Abedalhameed Al-khalaylah \\ Nares Musa Ahmad Hakouz \\ Jaafar Abu Abeeleh \\ Royal Medical Services, Jordan \\ Ahed J Alkhatib \\ Jordan University of Science and technology, Jordan \\ Mahmoud A Abu Abeeleh \\ The University of Jordan, Jordan
}

doi: 10.19044/esj.2016.v12n18p184 URL:http://dx.doi.org/10.19044/esj.2016.v12n18p184

\begin{abstract}
Introduction: Hyperglycemia and insulin resistance are common in critically ill patients, even if they have not previously had diabetes, and the risk of mortality or significant morbidity is high among those who are treated in the intensive care unit (ICU) for more than 5 days.

Objective: To assess the effect of glucose management protocol on mortality and morbidity

in a heterogeneous population of critically ill adult patients.

Design: A randomized controlled trial.

Setting: A 24-bed medical-surgical intensive care unit (ICU) for adult patients at King

Hussein Medical Center, the Royal Medical Services.

Methods: A total of 50 patients who were considered to need intensive care for at least three days, were randomly assigned into two groups. The intervention group subjects were to undergo a glucose control protocol with insulin infusion titrated to maintain blood glucose level in a target range of 120-160 mg/dL; except septic patients, in whom the target was higher, 160$180 \mathrm{mg} / \mathrm{dL}$. Patients in the second group (control group) were treated by a
\end{abstract}


conventional approach with reduction of blood glucose level only if the level was markedly elevated ( $>200 \mathrm{mg} / \mathrm{dL}$ ) to maintain blood glucose level in a target range of $180-200 \mathrm{mg} / \mathrm{dL}$.

Results: After adjustment for baseline characteristics the 2 groups of patients were well matched, for age, sex, prevalence of diabetes mellitus, HbA1c value and distribution of diagnoses; the only significant difference was in the percentage of cardiovascular dysfunction, which was higher in the intervention group $(p=0.047)$. After institution of the protocol, the mean blood glucose levels differed significantly between the two treatment groups during the study period $(143.70 \pm 12.78 \mathrm{mg} / \mathrm{dL}$ in the intervention group versus $175.56 \pm 14.07 \mathrm{mg} / \mathrm{dL}$ in the control group ( $p<0.001)$. And patients in the intervention group received a larger mean insulin dose $28.32 \pm 16.38$ units per day, vs. $14.60 \pm 12.26$ in the control group ( $p=0.001$ ). The difference in mortality between the two treatment groups was not significant at 28 days $(p=0.370)$ and at 60 days ( $p=0.555)$. No significant increase in hypoglycemia episodes was reported in our blood glucose level target.

Conclusion: The glucose management protocol resulted in significantly improved glycemic control and was not associated with increased rate of death or hypoglycemia.

Keywords: Diabetes, glucose control, insulin, intervention, randomized controlled trial

\section{Introduction}

\section{Stress induced hyperglycemia in critically ill patients}

Hyperglycemia determined by a high serum glucose level above the normal parameters and it is a frequent, almost universal transient, stressrelated finding. It occurs in the majority of patients admitted to the ICU, even those who did not previously suffer from diabetes. At the time of admission, it is associated with an increased morbidity and mortality in critically ill patients (Block et al., 2006). Critically ill patients are particularly prone to hyperglycemia because of the complex metabolic and hormonal changes associated with the stress response imposed by any type of acute illness or injury leading to what is called diabetes of injury (Marik and Raghavan, 2004).

\section{The concept of stress-induced hyperglycemia}

The concept of stress-induced hyperglycemia, typically defined as blood glucose (BG) concentrations $>200 \mathrm{mg} / \mathrm{dL}$, has been described for almost 150 years. Since there was no evidence of a causal relationship, the stress-induced hyperglycemia was only treated with exogenous insulin when 
it exceeded $12 \mathrm{mmol} / \mathrm{L}(220 \mathrm{mg} / \mathrm{dL})$. In patients with known diabetes, even higher levels were often tolerated (Mesotten and Berghe , 2003).

Moderate hyperglycemia was often viewed as a buffer against hypoglycemia-induced brain damage and beneficial adaptive response to life-threatening illness. It was thought to ensure adequate supply of glucose to the brain, to erythrocytes, and to injured tissues through an activation of the hypothalamic-pituitary-adrenal axis to provide substrates for vital organ function from endogenous stores (Mizock, 1995).

This notion was recently challenged, and the overall increase in glucose turnover to be not beneficial. In 2001, however, the critical care community was forced to reconsider this dogma, as a large randomized, controlled, clinical study "the Leuven study" showed that preventing even moderate hyperglycemia during critical illness substantially improved outcome (Berghe et al., 2001).

The fact that hyperglycemia persists despite abundantly released insulin was considered an argument in favor of tolerating moderately elevated blood glucose levels during critical illness. Overwhelming evidence in both surgical and medical ICU patients conclusively demonstrates that hyperglycemia is a marker of severity of illness and is also an independent determinant of bad outcome, and is associated with a number of lifethreatening complications and death. Indeed, if one considers hyperglycemia of injury as beneficial in promoting cellular glucose uptake in non-insulindependent tissues, tolerating modest degrees of hyperglycemia is beneficial (Shaw et al., 2005; Nasraway, 2006).

Patients in the intensive care unit (ICU) are predisposed to elevated blood glucose levels because of common clinical interventions, such as the use of corticosteroids, vasopressors, glucose-containing intravenous fluids used for drug or fluid administration, enteral or parenteral nutrition, and dialysis (Krinsley et al., 2005).

\section{Mortality and high admission glucose}

Kosiborod et al (2005) found a relation between high admission glucose and increased mortality in elderly patients hospitalized with acute myocardial infarction (Kosiborod et al., 2005). A retrospective study was conducted on all injured patients admitted to the surgical ICU for more than 48 hours. Nonsurvivors had higher average glucose than survivors $(p<0.03)$. In ICU the mortality rate for newly hyperglycemic patients approached one in three (Umpierrez et al., 2002). A retrospective analysis of a heterogeneous population of critically ill patients revealed that even a modest degree of hyperglycemia was associated with increased hospital mortality (Krinsley et al., 2003). 


\section{Controlling hyperglycemia in ICU patients}

Although extensive research efforts during the last decade focused on strategies to prevent or reverse the potentially lethal multiple organ failure, only few of them revealed positive results. One of these strategies is blood glucose control with insulin (Berghe., 2004). Another way for controlling hyperglycemia is by controlling the exogenous nutritional inputs (Chase et al., 2006).

\section{Study objectives}

The main objective of the current study is to assess the influence of the blood glucose level control on the morbidity and mortality of intensive care unit patients.

\section{Materials and methods}

\section{Study design and setting}

A randomized, controlled trial study was conducted to manage blood glucose, and adult medical and surgical ICU patients, who received treatment in the ICU for 3 or more consecutive days, at King Hussein Medical Center, the Royal Medical Services were involved.

\section{Study population}

Population of this study included ICU patients received at King Hussein Medical Center, the Royal Medical Services.

\section{Study sample}

A total of 50 patients were included in this study and assigned randomly into two groups: control group ( $\mathrm{N}=25$ patients) and intervention group ( $\mathrm{N}=25$ patient).

\section{Study procedure}

The study was approved by the Local Research Ethics Committee in the Royal Medical Services. The standard for obtaining informed consent for participation in the study was in the form of written informed consent from the conscious and comprehending patient, prior to enrollment in the study; however some patients were severely ill and/or were receiving sedative medications as part of their treatment. For those who were not able to provide consent, an explanatory statement was provided to their legal surrogate.

To ensure patient safety, the target blood glucose concentrations were closely monitored, and the results were known to the clinical staff treating the patients. As patient safety is paramount, it was not possible to blind the clinical staff in the ICU to treatment allocation. Eligible patients were 
enrolled into the study between 25th of June 2009 and 12th of October, 2009; and each patient followed for sixty days for living status.

Adults, who were expected to require treatment in the medical and surgical ICU for 3 or more consecutive days, and within 24 hours after admission to an intensive care unit, were eligible for the study.

\section{Inclusion criteria were if}

- $\quad$ Duration of required treatment in the ICU is 3 or more consecutive days after admission.

- $\quad$ Patients who had an arterial line or central line in situ or the placement of the lines was imminent as part of routine ICU management.

- $\quad$ Need for insulin therapy.

- Informed consent was approved by the patient or his/her legal surrogate.

\section{Exclusion criteria were if:}

\section{- $\quad$ Age is less than 18 years.}

- $\quad$ Imminent death (cardiac standstill or brain death anticipated in less than 24 hours.

- Patients were admitted to the ICU for treatment of diabetic ketoacidosis or for hyperosmolar state.

- $\quad \square$ Patients who had previously suffered hypoglycemia without a documented full neurological recovery.

- $\quad$ Patients who were considered at abnormally high risk of suffering hypoglycemia (e.g. known insulin secreting tumor or history of unexplained or recurrent hypoglycemia or fulminant hepatic failure).

- Patients cannot provide prior informed consent and there is documented evidence that the patient has no legal surrogate and it appears unlikely that the patient will regain consciousness or sufficient ability to provide delayed informed consent.

\section{Data collection and follow up}

Data collection included those variables necessary to define patient characteristics at baseline, the incidence and severity of hyperglycemia and hypoglycemia, and documentation of deaths and other serious adverse events during follow up. The information that were sought from the entire patients demographic and clinical data were collected from patients files, daily medication sheets, verbally from patients surrogate and clinical laboratory data sheets. All information were collected in a data collection form eligible patients were randomly assigned into two groups: the intervention and the control. 


\section{Statistical Analysis}

SAS, version 9.1, was used for statistical analysis. Clinical data were expressed as mean, median and as percentages. $P$ values less than 0.05 were considered significant. For univariate analysis of end points Chi-square test or Fisher's exact test. Continuous variables were compared with the use of unpaired t-test, or Wilcoxon rank-sum test. The primary analysis for death at 60 days and 28 days was performed with the use of an unadjusted chi-square test.

\section{Results}

\section{Study participants}

\section{Recruitment and follow up of study population}

A total of 54 patients were recruited in this randomized controlled study. Two patients were excluded as they did not meet the inclusion criteria and the other two patients were lost to follow-up as they were from abroad, and their data were not analyzed. All remaining patients $(n=50)$ were followed up for vital status, and they were randomly assigned to one of the two treatment groups: 25 to interventional glucose control (intervention group) and 25 to conventional glucose control (control group).

\section{The baseline characteristics of patients}

It was found that the baseline characteristics were almost similar between the treatment groups as shown in Table 1, no significant differences were found in the mean $( \pm S D)$ of age, the percentage of male patients, the mean $( \pm S D)$ of weight, body-mass index and of HbA1c value between the two groups $(p>0.05)$. No significant differences were detected in the percentage of operative admission between the intervention group (60\%) and the control group (68\%), and in the percentage of non- operative admissions between the two groups $(\mathrm{p}=0.55)$.

The percentage of patients admitted for operative causes was higher than those admitted for

medical causes in both groups. Difference in location before ICU admission was also not significant between the two groups $(p=0.178)$.

For organ dysfunction before randomization, no significant differences in respiratory, hepatic, coagulatory and renal dysfunctions were seen between the two groups ( $>>0.05)$. The only significant difference was in cardiovascular dysfunction, the percentage being higher in the intervention group $(p=0.047)$.

There were no significant differences in the percentages of patients on mechanical ventilation, those with history of diabetes mellitus type 2, previous treatment with insulin, previous treatment with systemic corticosteroids and smoking between the two groups ( $>>0.05)$. 
There was no history of diabetes mellitus type 1 in the two groups; all diabetic patients in the study were with history of diabetes mellitus type 2 . Subgroup classifications at randomization including severe sepsis and trauma were not significantly different between the two groups $(\mathrm{p}>0.05)$. Blood glucose level before randomization in the control group was not significantly different from that in the intervention group ( $>>0.05$ ).

Table 1: Baseline characteristics of study patients

\begin{tabular}{|c|c|c|c|}
\hline Variable & Intervention group & Control group & $p$-value \\
\hline Age - Yr, mean \pm SD & $58.28 \pm 13.19$ & $51.28 \pm 15.7$ & 0.94 \\
\hline Male sex (\%) & $72 \%$ & $60 \%$ & 0.37 \\
\hline Weight-kg, mean \pm SD & $81.76 \pm 12.04$ & $79.48 \pm 9.57$ & 0.46 \\
\hline Body-mass index, mean \pm SD & $28.14 \pm 2.71$ & $28.16 \pm 2.54$ & 0.97 \\
\hline $\begin{array}{l}\text { Reason for ICU admission (\%) } \\
\cdot \bullet \text { Operative } \\
\bullet \text { Nonoperative }\end{array}$ & $\begin{array}{l}60 \% \\
40 \%\end{array}$ & $\begin{array}{l}68 \% \\
32 \%\end{array}$ & 0.55 \\
\hline $\begin{array}{c}\text { Location before ICU admission } \\
(\%) \\
\text { • Emergency department } \\
\text { • Hospital floor } \\
\text { • Another hospital } \\
\text { • Operating room } \\
\end{array}$ & $\begin{array}{l}24 \% \\
24 \% \\
12 \% \\
40 \% \\
\end{array}$ & $\begin{array}{c}20 \% \\
8 \% \\
4 \% \\
68 \%\end{array}$ & 0.17 \\
\hline $\begin{array}{c}\text { Organ dysfunction }(\%) \\
\cdot \text { Respiratory } \\
\cdot \text { Coagulatory } \\
\cdot \text { Cardiovascular } \\
\cdot \text { Hepatic } \\
\cdot \text { Renal }\end{array}$ & $\begin{array}{l}88 \% \\
44 \% \\
60 \% \\
24 \% \\
28 \%\end{array}$ & $\begin{array}{l}84 \% \\
68 \% \\
32 \% \\
16 \% \\
20 \%\end{array}$ & $\begin{array}{l}0.68 \\
0.09 \\
0.04 \\
0.46 \\
0.50\end{array}$ \\
\hline Mechanical ventilation (\%) & $92 \%$ & $84 \%$ & 0.135 \\
\hline $\begin{array}{c}\text { History of diabetes mellitus Type } \\
2(\%)\end{array}$ & $60 \%$ & $36 \%$ & 0.093 \\
\hline $\begin{array}{c}\text { Previous treatment with insulin } \\
(\%)\end{array}$ & $32 \%$ & $16 \%$ & 0.185 \\
\hline $\begin{array}{l}\text { Previous treatment with systemic } \\
\text { corticosteroids (\%) }\end{array}$ & $8 \%$ & $4 \%$ & 0.551 \\
\hline $\begin{array}{c}\text { Subgroup classifications at } \\
\text { randomization }(\%) \\
\bullet \text { Severe sepsis } \\
\bullet \text { Trauma }\end{array}$ & $\begin{array}{l}12 \% \\
16 \%\end{array}$ & $\begin{array}{l}4 \% \\
16 \%\end{array}$ & $\begin{array}{c}0.297 \\
1\end{array}$ \\
\hline Smoking (\%) & $80 \%$ & $64 \%$ & 0.207 \\
\hline HbA1c value, mean \pm SD & $6.36 \pm 0.95$ & $6.40 \pm 0.81$ & 0.86 \\
\hline $\begin{array}{c}\text { Blood glucose level before } \\
\text { randomization } \mathrm{mg} / \mathrm{dL} \text {, mean } \pm \mathrm{SD}\end{array}$ & $259.44 \pm 31.02$ & $244.88 \pm 29.19$ & 0.09 \\
\hline
\end{tabular}

\section{Glucose control and treatment effects}

Patients enrolled in the intervention group were more likely than those in the control group to have received insulin (96\% versus $72 \%$, $p=0.02$ ), and they received a larger mean insulin dose $28.32 \pm 16.38$ units per day, vs. $14.60 \pm 12.26$ in the control group $(p=0.001)$. The median duration of 
the insulin treatment was significantly different between the two groups ( $p=0.022$ ). The time-weighted blood glucose level (with weighting based on the time difference between two consecutive measurements applied to the average of the two consecutive measurements) was computed for all the patients. The mean time-weighted blood glucose level was significantly lower in the intervention group than in the control group (143.70 \pm 12.78 versus $175.56 \pm 14.07 \mathrm{mg} / \mathrm{dL}, p<0.001)$. The morning blood glucose level was also significantly lower in the intervention group than the level in the control group (138.56 \pm 17.09 versus $174.04 \pm 16.69, p=0.001)$. Measures of glycemic control are shown in Table 2 and Figures 1 and 2. There was no significant difference in the percentage of patients who were treated with corticosteroids between the two groups $(p=0.568)$. Mortality rates decreased, but not significantly in intervention group compared with control group as measured at (Table 2).

Table 2: Blood glucose management and corticosteroid treatment

\begin{tabular}{|c|c|c|c|}
\hline Variable & Intervention group & Control group & $p$-value \\
\hline Treated with insulin (\%) & $96 \%$ & $72 \%$ & 0.0206 \\
\hline Insulin dose, units/day, & $28.32 \pm 16.38$ & $14.60 \pm 12.26$ & 0.0016 \\
mean \pm SD & $3(0-31)$ & $1(0-14)$ & 0.022 \\
\hline $\begin{array}{c}\text { Duration of insulin } \\
\text { (minimum-maximum) }\end{array}$ & $138.56 \pm 17.09$ & $174.04 \pm 16.69$ & 0.001 \\
\hline $\begin{array}{c}\text { Morning blood glucose, } \\
\text { mg/dL, mean } \pm \text { SD }\end{array}$ & $143.70 \pm 12.78$ & $175.56 \pm 14.07$ & $<0.001$ \\
\hline $\begin{array}{c}\text { Mean time-weighted } \\
\text { blood glucose level, } \\
\text { mg/dL, mean } \pm \text { SD }\end{array}$ & $28 \%$ & $40 \%$ & 0.550 \\
\hline $\begin{array}{c}\text { Corticosteroid treatment, \% } \\
\text { At day } 60\end{array}$ & $32 \%$ & $40 \%$ & 0.568 \\
\hline $\begin{array}{c}\text { Mortality rate (\%): } \\
\text { At day }\end{array}$ & $48 \%$ & & \\
\hline
\end{tabular}




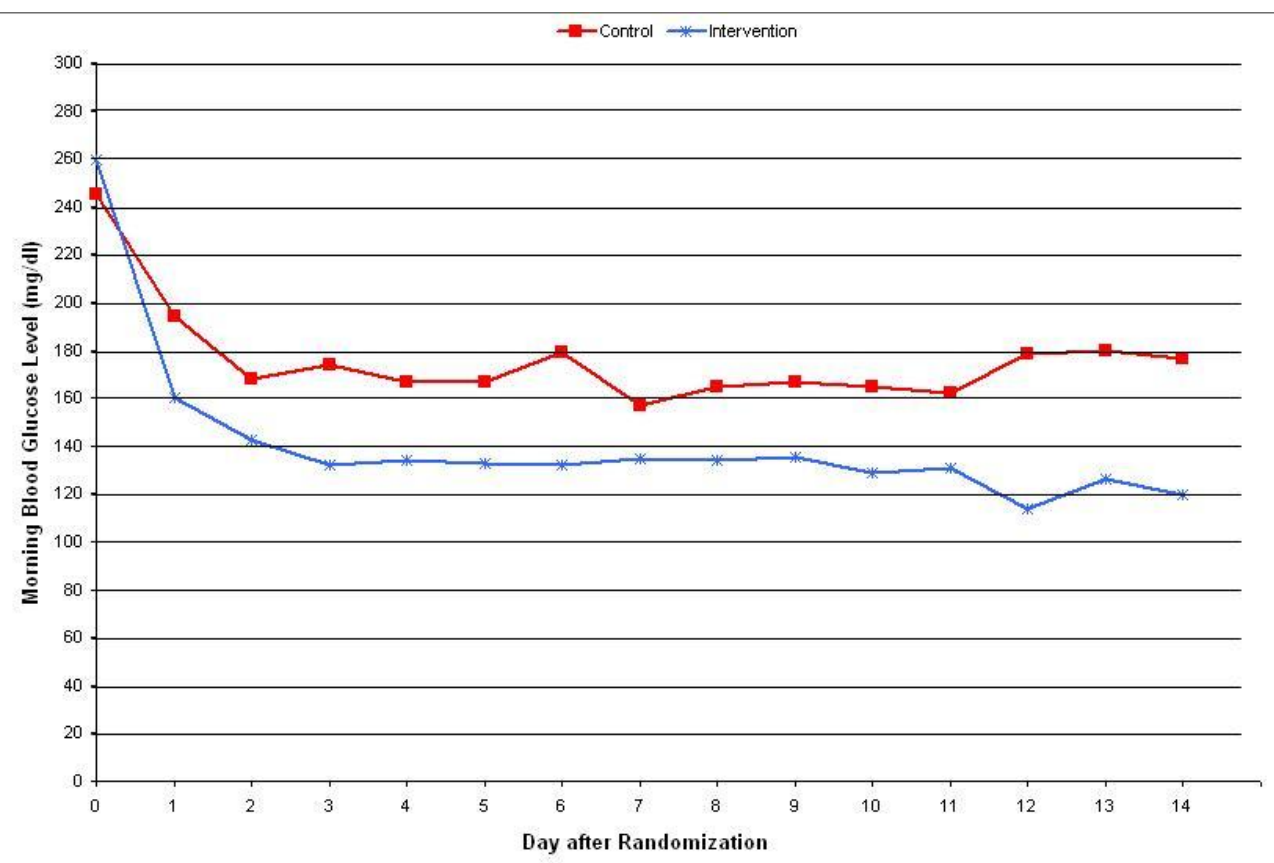

Figure 1: shows morning blood glucose levels over 14 days. Baseline data are the averages of the last blood glucose measurements obtained before randomization; day 1 data are the average levels from the time of randomization to the end of the day of randomization.

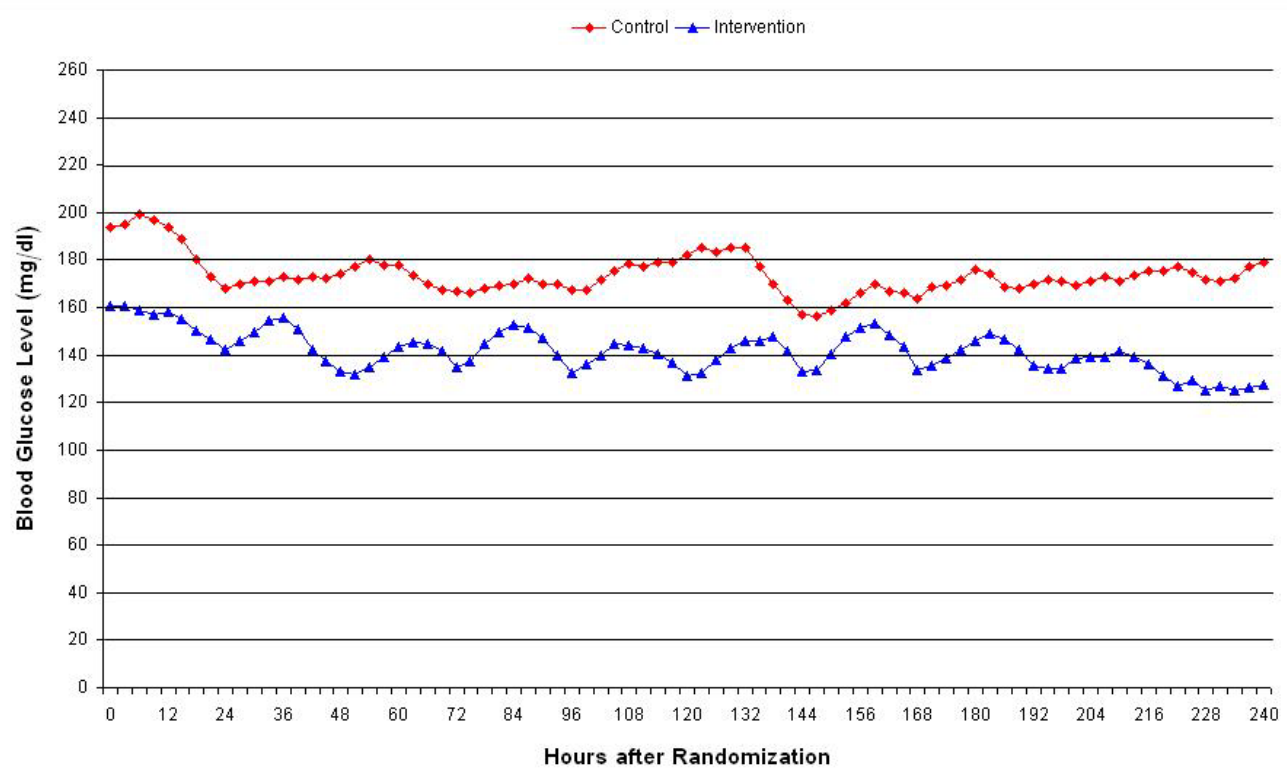

Figure 2: The mean blood glucose levels of the two groups. Baseline data are the averages of blood glucose levels from the time of randomization to the end of the day of randomization for all patients in each group, then averages of daily blood glucose levels until ten days after randomization. Averages of the blood glucose level were significantly lower in the intervention group from those of the control group $(p<0.001)$. 


\section{Discussion}

The apparent contradiction between the adverse effects of hyperglycemia and increased administration of insulin provokes debate over the most appropriate target for glucose control. Controlling hyperglycemia without being too tight will result in the most benefit without increasing the risk for severe hypoglycemia (Bochicchio and Scalea, 2008).

A Joint Statement From the American Diabetes Association (2008) and American Association of Clinical Endocrinologists (2009) announced that it is important to consider that the severely ill patients in NICE-SUGAR trial -that reported an increase in mortality rate, and episodes of severe hypoglycemia with tight glycemic control- were treated intensively with intravenous insulin to very tight targets (target glucose level was 81-108 $\mathrm{mg} / \mathrm{dL}$ ) compared to a control group whose glucose control was good (average glucose $144 \mathrm{mg} / \mathrm{dL}$ ). This study should not lead to an abandonment of the concept of good glucose management in the hospital setting.

In light of the recently published NICE-SUGAR data, a systematic review and a new meta-analysis provide an updated estimate of the effect of such therapy on the risk of hypoglycemia and death. It has suggested that TGC protocols offer limited if any benefits in critically ill adults and revealed that these protocols resulted in a 3- to 5-fold increased risk of hypoglycemia. The meta-analysis examined 29 randomized controlled trials that met the predefined inclusion criteria with strict glycemic goals. Of the 27 trials that examined mortality as an endpoint, 16 favored TGC and 11 favored usual care, but the reductions in relative risk were statistically significant (95\% confidence) in only 2 of the 16 favoring TGC and in none of the 11 favoring usual care. The only outcome for which TGC demonstrated a significantly reduced risk was the development of septicemia. This was seen in surgical intensive care patients but not in medical ICU which cannot exclude the possibility that some patients may benefit from intensive insulin therapy (Donald et al., 2009).

In our study a new range of glucose level was set to control hyperglycemia with an insulin infusion pump protocol used in the intervention group. A goal was to maintain blood glucose level within range of $120-160 \mathrm{mg} / \mathrm{dL}$, for ICU patients in general in the intervention group, and the range of $160-180 \mathrm{mg} / \mathrm{dL}$ was set for septic patients, to prevent hypoglycemia, which is risky in this particular ICU population. While conventional treatment with an insulin infusion pump was maintained in the control group; that is to maintain blood glucose level less than $200 \mathrm{mg} / \mathrm{dL}$ for ICU patients in a target range of $180-200 \mathrm{mg} / \mathrm{dL}$.

The above ranges for the intervention group were higher than the TGC protocol since negative outcomes reported in the NICE-SUGAR study increased the need to target safer blood glucose level at the same time 
controlling hyperglycemia and preventing bad outcomes; a glucose levels in the mid-100s. Our goal was set before the recommendations by ADA and AACE were declared (Moghissi et al., 2009).

The management of blood glucose levels was standardized. Nearly all patients received their assigned treatment. The mean blood glucose levels differed significantly between the two treatment groups during the study period (143.70 \pm 12.78 versus $175.56 \pm 14.07 \mathrm{mg} / \mathrm{dL}, p<0.001)$. When insulin resistance decreased, lower insulin rates were able to maintain better blood glucose levels.

The difference in mortality remained not significant after adjustment for potential confounders at 28 days $(p=0.370)$, and at 60 days $(p=0.555)$, between two groups in our study. This finding agrees with the result of a meta-analysis stating that the different targets of intensive insulin therapy (glucose level [ $6.1 \mathrm{mmol} / \mathrm{L}$ versus [ $8.3 \mathrm{mmol} / \mathrm{L}$ ) did not influence either mortality (Fahey et al., 2009). It was noticed by secondary subgroup analysis for the primary outcome that the percentage of death was significantly higher in medical ICU patients than surgical ICU patients $(p=0.015)$, indicating that surgical patients may benefit more from insulin treatment. As found in previous studies (Berghe et al., 2001, He et al., 2007) and a meta-analysis (Donald et al., 2009).

\section{Conclusion}

Hyperglycemia develops commonly in the critically ill and impacts outcome in patients with diabetes but, even more so, in patients with stressinduced hyperglycemia. Our trial showed that a blood glucose target of less than 160 mg per deciliter in general, and target of less than 180 for septic patients, did not significantly increase mortality more than a target of less than $200 \mathrm{mg}$ /per deciliter among critically ill adult patients. Mortality rates were less in intervention group than in control group, but this was not statistically significant ( $\mathrm{p}>0.05)$.

\section{References:}

American Diabetes Association (ADA). (2008). Standards of medical care in diabetes. and range of blood glucose are also associated with ICU mortality. Critical Care Medicine; 32:A125.

Bochicchio GV, Scalea TM. (2008). Glycemic control in the ICU. Adv Surg; 42:261-75.

Chase JG, Shaw GM, Hann CE, LeCompte A, Lonergan T, Willacy M, Wong XW, Lin J, Daren K. Heyland, MD, Deborah J. Cook, MD MSc, Atul Malhotra, MD, Rupinder Dhaliwal, RD, William R. Henderson, MD, Dean R. Chittock, MD MS(Epi), Simon Finfer, MBBS, and Daniel Talmor, MD MPH. (2009). Intensive insulin therapy and mortality among critically ill 
patients: a meta-analysis including NICE-SUGAR study data.CMAJ; 14; 180(8): 821-827.

De Block C, Manuel-Y-Keenoy B, Van Gaal L, Rogiers P. (2006). Intensive insulin therapy in the intensive care unit: assessment by continuous glucose monitoring. Diabetes Care; 29(8):1750-6.

Donald E.G. Griesdale, MD MPH, Russell J. de Souza, RD MSc, Rob M. van Dam, PhD, Daren K. Heyland, MD, Deborah J. Cook, MD MSc, Atul Malhotra, MD, Rupinder Dhaliwal, RD, William R. Henderson, MD, Dean R. Chittock, MD MS(Epi), Simon Finfer, MBBS, and Daniel Talmor, MD MPH. (2009). Intensive insulin therapy and mortality among critically ill patients: a meta-analysis including NICE-SUGAR study data.CMAJ; 14; 180(8): 821-827.Fahy BG, Sheehy AM, Coursin DB. (2009). Glucose control in the intensive care unit. Crit Care Med.; 37(5):1769-76.

He W, Zhang TY, Zhou H, et al. (2007). Impact of intensive insulin therapy on surgical critically ill patients [Chinese]. Zhonghua Wai Ke Za Zhi; 45:1052-4.

Kosiborod M, Rathore SS, Inzucchi SE, Masoudi FA, Wang Y, Havranek EP, Krumholz HM (2005). Admission glucose and mortality in elderly patients hospitalized with acute myocardial infarction: implications for patients with and without recognized diabetes. Circulation; 111(23):3078-86. Krinsley JS (2003). Association between hyperglycemia and increased hospital mortality in a heterogeneous population of critically ill patients. Mayo Clin Proc; 78(12):1471-8.

Krinsley JS. (2005). Effect of an intensive glucose management protocol on the mortality of critically ill adult patients. Mayo Clinic Proc. 79(8):9921000. Erratum in: Mayo Clinic Proc;80(8):1101.

Lotz T. (2006). Clinical validation of a model-based glycaemic control design approach and comparison to other clinical protocols. Conf Proc IEEE Eng Med Biol Soc; 1:59-62.

Marik E, Raghavan M. (2004). Stress-hyperglycemia, insulin and immunomodulation in sepsis. Intensive Care Med; 30(5):748-56.

Mesotten D, Van den Berghe G. (2003). Clinical potential of insulin therapy in critically ill patients.Drugs Review; (7):625-36.

Mizock BA: (1995). Alterations in carbohydrate metabolism during stress: a review of the literature. Am J Med; 98(1):75-84.

Moghissi ES, Korytkowski MT, DiNardo M, Einhorn D, Hellman R, Hirsch IB, Inzucchi SE, Ismail-Beigi F, Kirkman MS, Umpierrez GE; American Association of Clinical Endocrinologists; American Diabetes Association. (2009). American Association of Clinical Endocrinologists, and American Diabetes Association consensus statement on inpatient glycemic control. Diabetes Care; 32(6):1119-31. 
Nasraway SA Jr. (2006). Hyperglycemia during critical illness. J Parenter Enteral Nutr; sepsis. Intensive Care Med; 30(5):748-56.

Shaw, GM; Chase, JG; Lee, DS; Bloomfield, M; Doran, CV; Lin, J; Lotz, T. (2005). Peak and range of blood glucose are also associated with ICU mortality. Critical Care Medicine; 32:A125.

Umpierrez GE, Isaacs SD, Bazargan N, You X, Thaler LM, Kitabchi AE. (2002). Hyperglycemia: an independent marker of inhospital mortality in patients with undiagnosed diabetes. J Clin Endocrinol Metab; 87(3):978982.

Van den Berghe G, Wouters P, Weekers F, Verwaest C, Bruyninckx F, Schetz M, Vlasselaers D, Ferdinande P, Lauwers P, Bouillon R. (2001). Intensive insulin therapy in the critically ill patients. $\mathrm{N}$ Engl $\mathrm{J}$ Med; 345(19):1359-67.

Van den Berghe G, Wouters P, Weekers F, Verwaest C, Bruyninckx F, Schetz M, Vlasselaers D, Ferdinande P, Lauwers P, Bouillon R. (2001). Intensive insulin therapy in the critically ill patients. $\mathrm{N}$ Engl $\mathrm{J}$ Med; 345(19):1359-67.

Van den Berghe G. (2004). How does blood glucose control with insulin save lives in intensive care? J Clin Invest; 114:1187-1195. 